\title{
Comparison of Outcome of Decompressive Craniectomy with Wide Dural Flap Duraplasty Versus Dural Slits in the Management of Post Traumatic Acute Subdural Hematoma in Terms of Postoperative CSF Leak GHAYUR ABBAS, ${ }^{1}$ RIFFATULLAH KHAN, ${ }^{2}$ USAMA BIN ZUBAIR ${ }^{1}$ SAJID NAZEER BHATTI ${ }^{1}$ \\ ${ }^{1}$ Pakistan Institute of Medical Sciences (PIMS), Islamabad \\ ${ }^{2}$ Abbottabad Medical Complex, Abbottabad-Pakistan \\ DOI: https://doi.org/10.36552/pjns.v23i3.350
}

\begin{abstract}
Objective: To compare the frequency of postoperative cerebrospinal fluid (CSF) leak after decompressive craniectomy with wide dural flap duraplasty versus dural slits in patients with post traumatic acute subdural hematoma.

Material and Methods: The study was conducted from August 2017 to February 2018 in the Department of Neurosurgery, PIMS, Islamabad. A total of ninety-two $(n=92)$ adult patients of either gender between age 15-55 years presented with isolated, unilateral traumatic acute sub dural hematoma (ASDH) with midline shift of $5 \mathrm{~mm}$ were categorized into 2 groups; Group A (DC with open dural flap) and Group B (DC with dural slits). Patients were observed for CSF leakage for four weeks.

Results: Results showed that the overall frequency of CSF leak was not significantly different in both groups and revealed that the CSF leak was observed in 10.9\% $(n=5 / 46)$ in group A (DC plus open dural flap) and in $21.7 \%$ $(n=10 / 46)$ in group $B(D C$ plus dural slits $)(P=0.158)$. The difference was not significant in terms of frequency of CSF leak in both groups when results were stratified with respect to gender, age, duration of trauma and baseline GCS. P value (chi-square) was found to be $>0.05$ in all cases.

Conclusions: The postoperative CSF leak was observed in higher percentages in patients who underwent DC with dural slits as compared to the patients who underwent DC with open dural flaps for surgical management of $A S D H$. The difference, however, was not statistically significant.
\end{abstract}

Keywords: Decompressive craniectomy, acute subdural hematoma, CSF leak.

\section{INTRODUCTION}

Acute Subdural hematoma (SDH), is caused by tearing of the bridging vessels usually veins that runs from the brain surface to the dural sinuses. Trauma to the head being the commonest of SDH, with the majority of cases related to Road traffic accidents, assaults and fall from height. ${ }^{1}$ In Cases with closed head trauma, sudden acceleration/deceleration force causes injury to critical vessels including arteries, veins, or brain parenchyma. Coma is an initial presentation in approximately $50 \%$ of cases at the time of injury. And with approximately 12 to $38 \%$ of patients having transient "lucid interval" after the initial insult which is followed by a progressive neurologic deterioration to coma. $^{2}$

CT scan head being the most commonly prescribed imaging modality for the diagnosis of acute subdural hematoma, which is seen as a high-density subdural crescent shape collection. Acute symptomatic subdural hematoma is a neurosurgical emergency requiring surgical intervention to prevent secondary brain injury and death due to expansion of hematoma, 
raised intracranial pressure and brain herniation. ${ }^{3}$

Most of the studies recommend urgent evacuation of hematoma in patients with midline shift of $>5 \mathrm{~mm}$ or clot thickness of $>10 \mathrm{~mm}^{4}$ Different techniques can be employed for evacuation of symptomatic acute $\mathrm{SDH}$, including decompressive craniectomy (DC), burr hole trephination or simple craniotomy and evacuation of hematoma, however, only few studies compares different surgical methods. ${ }^{5}$ DC involves removal of skull bone along with clot, but without replacing the bone due to possible expansion of brain due to edema. In one technique Dura matter is widely opened in $\mathrm{C}$ shaped manner. This procedure gives advantage to the surgeon by immediately lowering raised intracranial pressure by providing more space to the edematous brain and allowing surgeon with the proper exposure of hematoma. ${ }^{6}$ However, herniation of edematous brain was observed in many cases through the craniectomy defect. In another technique multiple linear dural slits are made parallel to the dural vessels. The multi-dural slits allowed slow removal of acute subdural hematoma by oozing of hematoma and CSF preventing herniation of brain, thus preventing secondary injury to the brain. However, this technique is associated with higher risk of post-operative CSF leaks. ${ }^{7}$ In a recent study, Khan B et al reported that patients who undergone decompressive craniectomy with expansile duraplasty for evacuation of ASDH, CSF leak was observed in $6.5 \%$ of patients during the post-operative follow up period, while in patients who undergone decompressive craniectomy with dural slits CSF leak was observed in $28.6 \%$ of patients during the follow up period. ${ }^{8}$ The risk of life threatening bacterial meningitis persists as long as the CSF leak is active. The reported incidence of meningitis in patients with post-operative CSF leak is around $10 \%$ and antibiotic prophylaxis should be given or not is still a controversy. $^{9}$

This study will be helpful in identifying the better technique in terms of lesser risk of post-operative CSF leak after surgical management of acute SDH.

\section{MATERIALS AND METHODS}

\section{Study Design and Sampling}

This RCT was conducted at Neurosurgery department, PIMS, Islamabad for Six months (05-08-2017 to 0402-2018). WHO sample size calculator (2.2 b)was used for sample size with Power of test $80 \%$, Level of significance $5 \%$, anticipated population proportion I:
6.5\% and Anticipated Population Proportion II: $28.6 \% .^{8}$

The sample size calculated came out to be 46 patients in each group. Total sample size was $46+46=$ 92. Consecutive non probability was used as sampling technique.

\section{Inclusion Criteria}

Patients with both genders who presented with unilateral isolated, traumatic Acute Subdural hematoma with midline shift of $5 \mathrm{~mm}$ (diagnosed on CT scan) in an age group from 15 to 55 years were included.

\section{Exclusion Criteria}

Patients excluded were those with GCS of $\leq 4 / 15$ or those who presented more than 12 hours after the injury or those with $\mathrm{H} / \mathrm{O}$ previous brain surgery or patients with $\mathrm{H} / \mathrm{O}$ of comorbid like hypertension and diabetes.

\section{Data Collection}

Hospital ethical committee permission and approval were taken for the study. All Head injury patients presenting to the ER were enrolled in this study who fulfil the inclusion criteria and were reviewed by senior neurosurgeon for appropriate management. Informed consent taken in written form from the patient/guardian. All patients were randomly allotted to two separate groups using the lottery method. Patients in group A underwent craniotomy with open dural flap while patients in Group B were operated via dural slits. The patients were observed for CSF leakage for four weeks after the surgery in both groups. Antibiotics were given to all the patients to reduce the risk of infection. If a CSF leak occurred, it was managed either conservatively (head-end elevation, pressure dressings, hyper-osmolar/diuretic therapy) or through interventions (frequent lumbar puncture, continuous lumbar drainage, EVD placement, local drain placement, revision) where necessary. All the information was written down on the prescribed Proforma. Exclusion criteria who referred consent for study.

\section{Data Analysis}

The data entered using 22.0 version of SPSS. Quantitative variables like, duration of trauma, age and baseline GCS were measured as mean \pm SD. 
Frequencies and percentages were calculated for gender and frequency of CSF leak in both groups. Frequency of CSF leak in both groups was compared by employing Chi-square test. $P$-value considered significant at $\leq 0.05$. Effect modifiers like age, gender, duration of trauma and baseline GCS was controlled by stratification. Poststratification Chi-square test was applied and $P$-value $\leq 0.05$ was considered significant.
Table 1: CSF leak in both of the study groups.

\begin{tabular}{|c|c|c|c|c|}
\hline \multirow[b]{2}{*}{ CSF Leak } & \multicolumn{2}{|c|}{ Groups } & \multirow[b]{2}{*}{ Total } & \multirow{2}{*}{$\begin{array}{c}P \text {-Value } \\
\text { Chi-Square }\end{array}$} \\
\hline & $\begin{array}{c}\text { DC with } \\
\text { Open Dural Flap }\end{array}$ & $\begin{array}{c}\text { DC with Dural } \\
\text { Slits }\end{array}$ & & \\
\hline Present & $\begin{array}{c}5 \\
10.9 \%\end{array}$ & $\begin{array}{l}10 \\
21.7 \%\end{array}$ & $\begin{array}{l}15 \\
16.3 \%\end{array}$ & \multirow{3}{*}{0.158} \\
\hline Absent & $\begin{array}{l}41 \\
89.1 \% \\
\end{array}$ & $\begin{array}{l}36 \\
78.3 \% \\
\end{array}$ & $\begin{array}{l}77 \\
83.7 \% \\
\end{array}$ & \\
\hline Total & $\begin{array}{c}46 \\
100.0 \%\end{array}$ & $\begin{array}{c}46 \\
100.0 \%\end{array}$ & $\begin{array}{c}92 \\
100.0 \%\end{array}$ & \\
\hline
\end{tabular}

\section{RESULTS}

A total of ninety-two $(n=92)$ adult patients of either gender between age 15 - 55 years presented with unilateral isolated traumatic ASDH with midline shift of $5 \mathrm{~mm}$ (diagnosed on CT scan) were enrolled and equally divided into two groups. Table 1 shows that the overall frequency of CSF leak was not significantly different in both groups and revealed that the CSF leak was observed in $10.9 \%(\mathrm{n}=5 / 46)$ in group A (DC with open dural flap) and in $21.7 \%$ ( $\mathrm{n}=$ $10 / 46)$ in group $B$ (DC with dural slits) $(P=0.158)$. Frequency of CSF leak in both groups did not show

Table 2: Stratification based on gender.

\begin{tabular}{|c|c|c|c|c|c|}
\hline \multirow{2}{*}{ Gender } & \multirow{2}{*}{ CSF Leak } & \multicolumn{2}{|c|}{ Groups } & \multirow{2}{*}{ Total } & \multirow{2}{*}{$\begin{array}{c}P \text {-Value } \\
\text { Chi-Square }\end{array}$} \\
\hline & & DC with Open Dural Flap & DC with Dural Slits & & \\
\hline \multirow{5}{*}{ Males } & & 4 & 10 & 14 & \multirow{5}{*}{0.077} \\
\hline & Present & $10.3 \%$ & $25.6 \%$ & $17.9 \%$ & \\
\hline & & 35 & 29 & 64 & \\
\hline & Absent & $89.7 \%$ & $74.4 \%$ & $82.1 \%$ & \\
\hline & Total & $\begin{array}{c}39 \\
100.0 \%\end{array}$ & $\begin{array}{c}39 \\
100.0 \%\end{array}$ & $\begin{array}{c}78 \\
100.0 \%\end{array}$ & \\
\hline \multirow{6}{*}{ Females } & & 1 & 0 & 1 & \multirow{6}{*}{0.299} \\
\hline & Present & $14.3 \%$ & $.0 \%$ & $7.1 \%$ & \\
\hline & Ab & 6 & 7 & 13 & \\
\hline & Absent & $85.7 \%$ & $100.0 \%$ & $92.9 \%$ & \\
\hline & Total & 7 & 7 & 14 & \\
\hline & Iotal & $100.0 \%$ & $100.0 \%$ & $100.0 \%$ & \\
\hline
\end{tabular}

Table 3: Stratification based on age.

\begin{tabular}{|l|l|c|c|c|c|}
\hline \multirow{2}{*}{ Age } & \multirow{2}{*}{ CSF Leak } & \multicolumn{2}{|c|}{ Groups } & \multirow{2}{*}{ Total } & $\begin{array}{c}\text { P-Value } \\
\text { Chi-Square }\end{array}$ \\
\cline { 3 - 6 } & & DC with Open Dural Flap & DC with Dural Slits & & 8 \\
\multirow{3}{*}{$15-30$ Years } & Present & 1 & 7 & $18.9 \%$ & 0.210 \\
\cline { 2 - 5 } & Absent & $5.9 \%$ & 30 & 46 & \\
& & 16 & $81.1 \%$ & $85.2 \%$ & \\
\hline
\end{tabular}


Ghayur Abbas, et al

\begin{tabular}{|c|l|c|c|c|c|}
\hline \multirow{3}{*}{} & Total & 17 & 37 & 54 & \\
\hline \multirow{5}{*}{$31-55$ Years } & Present & $100.0 \%$ & $100.0 \%$ & $100.0 \%$ & \\
\cline { 2 - 5 } & \multirow{3}{*}{ Absent } & 4 & 3 & 7 & \\
& & $13.8 \%$ & $33.3 \%$ & $18.4 \%$ & \\
\cline { 2 - 5 } & \multirow{2}{*}{ Total } & 25 & 6 & 31 & \multirow{2}{*}{0.186} \\
& & $86.2 \%$ & $66.7 \%$ & $81.6 \%$ & \\
& & 29 & 9 & 38 & \\
\hline
\end{tabular}

Table 4: Stratification based on duration.

\begin{tabular}{|c|c|c|c|c|c|}
\hline \multirow{2}{*}{$\begin{array}{l}\text { Duration of } \\
\text { Trauma }\end{array}$} & \multirow{2}{*}{ CSF Leak } & \multicolumn{2}{|c|}{ Groups } & \multirow{2}{*}{ Total } & \multirow{2}{*}{$\begin{array}{c}P \text {-Value } \\
\text { Chi-Square }\end{array}$} \\
\hline & & DC with Open Dural Flap & DC with Dural Slits & & \\
\hline \multirow{4}{*}{$<6$ Hours } & Present & 4 & & 14 & \multirow{4}{*}{0.107} \\
\hline & & $10.3 \%$ & $23.8 \%$ & $17.3 \%$ & \\
\hline & Absent & $\begin{array}{l}35 \\
89.7 \%\end{array}$ & $\begin{array}{l}32 \\
76.2 \%\end{array}$ & $\begin{array}{l}67 \\
82.7 \%\end{array}$ & \\
\hline & Total & $\begin{array}{c}39 \\
100.0 \%\end{array}$ & $\begin{array}{c}42 \\
100.0 \%\end{array}$ & $\begin{array}{c}81 \\
100.0 \%\end{array}$ & \\
\hline \multirow{3}{*}{ 6-12 Hours } & Present & $\begin{array}{c}1 \\
14.3 \%\end{array}$ & $\begin{array}{l}0 \\
.0 \%\end{array}$ & $\begin{array}{l}1 \\
9.1 \%\end{array}$ & \multirow{3}{*}{0.428} \\
\hline & Absent & $\begin{array}{c}6 \\
85.7 \%\end{array}$ & $\begin{array}{c}4 \\
100.0 \%\end{array}$ & $\begin{array}{l}10 \\
90.9 \%\end{array}$ & \\
\hline & Total & $\begin{array}{c}7 \\
100.0 \%\end{array}$ & $\begin{array}{c}4 \\
100.0 \%\end{array}$ & $\begin{array}{c}11 \\
100.0 \%\end{array}$ & \\
\hline
\end{tabular}

Table 5: Stratification based on baseline GCS.

\begin{tabular}{|c|c|c|c|c|c|}
\hline \multirow{2}{*}{ Baseline GCS } & \multirow{2}{*}{ CSF Leak } & \multicolumn{2}{|c|}{ Groups } & \multirow{2}{*}{ Total } & \multirow{2}{*}{$\begin{array}{c}P \text {-Value } \\
\text { Chi-Square }\end{array}$} \\
\hline & & DC with Open Dural Flap & DC with Dural Slits & & \\
\hline \multirow{3}{*}{$5-9$} & Present & $\begin{array}{c}5 \\
14.3 \% \\
\end{array}$ & \begin{tabular}{|c|}
8 \\
$25.0 \%$ \\
\end{tabular} & $\begin{array}{l}13 \\
19.4 \% \\
\end{array}$ & \multirow{3}{*}{0.268} \\
\hline & Absent & $\begin{array}{l}30 \\
85.7 \%\end{array}$ & $\begin{array}{l}24 \\
75.0 \%\end{array}$ & $\begin{array}{l}54 \\
80.6 \%\end{array}$ & \\
\hline & Total & $\begin{array}{c}35 \\
100.0 \% \\
\end{array}$ & $\begin{array}{c}32 \\
100.0 \% \\
\end{array}$ & $\begin{array}{c}67 \\
100.0 \% \\
\end{array}$ & \\
\hline \multirow{3}{*}{$10-15$} & Present & $\begin{array}{l}0 \\
.0 \% \\
\end{array}$ & $\begin{array}{c}2 \\
14.3 \% \\
\end{array}$ & $\begin{array}{l}2 \\
8.0 \% \\
\end{array}$ & \multirow{3}{*}{0.191} \\
\hline & Absent & $\begin{array}{c}11 \\
100.0 \%\end{array}$ & $\begin{array}{l}12 \\
85.7 \%\end{array}$ & $\begin{array}{l}23 \\
92.0 \%\end{array}$ & \\
\hline & Total & $\begin{array}{c}11 \\
100.0 \%\end{array}$ & $\begin{array}{c}14 \\
100.0 \%\end{array}$ & $\begin{array}{c}25 \\
100.0 \%\end{array}$ & \\
\hline
\end{tabular}


any significant difference when results were stratified with respect to age, gender, duration of trauma and baseline GCS (table 2-5). $P$ value (chi-square) was found to be $>0.05$ in all cases.

\section{DISCUSSION}

The surgical intervention required for evacuation of symptomatic acute subdural hematoma include different techniques, like, simple craniotomy and evacuation, burr-hole trephination or decompressive craniectomy. The DC involves removal of skull bone along with clot, but without replacing the bone due to possible expansion of the brain due to edema. This procedure has the advantage that it immediately decreases the raised intracranial pressure by giving space in the brain and allowing surgeon with the proper exposure of hematoma. However, a marked herniation of edematous brain was observed in many cases through the craniectomy. In another technique multiple linear dural slits are made parallel to the dural vessels. The multi-dural slits allowed slow removal of acute subdural hematoma by oozing of hematoma and CSF preventing herniation of the brain, thus preventing secondary injury to the brain. However, this technique is associated with higher risk of postoperative CSF leaks. In the current analysis, we planned to compare the frequency of postoperative CSF leak after decompressive craniectomy with wide dural flap duraplasty versus dural slits in patients with post traumatic acute subdural hematoma. Our results showed that the overall frequency of CSF leak was not significantly different in both groups and revealed that CSF leak was observed in $10.9 \%(n=5 / 46)$ in group A (DC with open dural flap) and in $21.7 \%(\mathrm{n}=10 / 46)$ in group B (DC with dural slits) $(P=0.158)$.

Our results are in similar with already published data. Khan B, et al in their randomized control study reported that patients who underwent decompressive craniectomy with expansile duraplasty for evacuation of ASDH, CSF leak was observed in $6.5 \%$ of patients during the post-operative follow up period, while in patients who underwent decompressive craniectomy with dural slits CSF leak was observed in $28.6 \%$ of patients during the follow up period. ${ }^{8}$

Bhat et al prospectively assessed 120 patients during a duration of 3 years with severe traumatic acute SDH, with one group using wide DC with duralstabs in 60 cases with another group using conventional dural opening (open dural flap) and removal of acute subdural hematoma in 60 controls. They found the overall survival of $78.3 \%$ with the dural-stab group (case-study), with $43.3 \%$ of good recovery and with the mortality (13/60) of $21.6 \%$ as compared to open dural flap (control) group with $40 \%$ survival, good recovery of $11.6 \%$ and with the mortality (36/60) of $60 \%$. The open dural flap technique proved dangerous in a traumatic and edematous brain. This dural-stabs technique proved to be much effective in increasing overall survival of patients with low GCS. In conclusion, a simple decompressive craniectomy alone does not provide more benefit and an open dural flap is full of risk in such patients. ${ }^{0-12}$

In a recent systematic literature review Barthélemy et al has evaluated decompressive craniectomy after severe TBI, by comparing the literature with first major RCT on this topic (DECRA). They found that when a comparison was done between Decompressive Craniectomy with multiple dural stabs and DC with open dural flap, dural stab group was found to have a significant advantage in mortality and GOS. They did not analyze the early complications like a CSF leak in different DC techniques. ${ }^{7,16}$

Subsequently, Bhat et al analyzed evacuation of acute SDH by a combination of DC and multi-dural stabs (SKIMS-Technique) without brain herniation and lacerations in low GCS score patients. Survival in multi-dural stab group was $77.31 \%$ (92/119) with $42.02 \%$ (50/119) good recovery and $22.69 \%$ (27/119) mortality as compared with survival of $46.23 \%$ (49/106) in open dural flap (control) group with good recovery in $15.09 \%$ (16/106) and $53.77 \%$ (57/106). They found DC with multi-dural stabs, much effective in terms of survival. They did not consider the early complication like CSF leaks in those patients. ${ }^{\text {? }}$

In summary, several studies have proved that DC with dural slits is associated with better treatment outcome and overall survival when compared with DC with open dural flaps. There are not much studies available on comparing the rate of CSF leak among both the techniques. In our study, the CSF leak has been observed in higher percentages in patients who underwent DC with dural slits as compared to the patients who underwent DC with open dural flaps. However, the difference was not statistically significant. Keeping in view the fact that DC with dural slits prevented herniation and thus preventing secondary insult to the brain, this technique could be a safer choice in surgical management of acute SDH. 
Further studies, nonetheless, are needed to validate it in routine clinical practice.

\section{CONCLUSIONS}

CSF leak was observed in higher percentages in patients who underwent DC with dural slits as compared to the patients who underwent DC with open dural flaps. The difference, however, was not statistically significant.

\section{Additional Information}

Disclosures: Authors report no conflict of interest.

Human Subjects: Consent was obtained by all patients/ participants in this study.

\section{Conflicts of Interest:}

In compliance with the ICMJE uniform disclosure form, all authors declare the following:

Financial Relationships: All authors have declared that they have no financial relationships at present or within the previous three years with any organizations that might have an interest in the submitted work.

Other Relationships: All authors have declared that there are no other relationships or activities that could appear to have influenced the submitted work.

\section{Address for Correspondence: Dr. Ghayur Abbas \\ Resident Neurosurgeon, PIMS, Islamabad-Pakistan Email: ghayurabbas02@gmail.com}

\section{REFERENCES}

1. Ryan CG, Thompson RE, Temkin NR, Crane PK, Ellenbogen RG, Elmore JG. Acute traumatic subdural hematoma: current mortality and functional outcomes in adult patients at a Level I trauma center. J Trauma Acute Care Surg. 2012; 73 (5): 1348-54.

2. Leitgeb J, Mauritz W, Brazinova A, Janciak I, Majdan $\mathrm{M}$, Wilbacher I, et al. Outcome after severe brain trauma due to acute subdural hematoma. J Neurosurg. 2012; 117 (2): 324-33.

3. Mulligan P, Raore B, Liu S, Olson JJ. Neurological and functional outcomes of subdural hematoma evacuation in patients over 70 years of age. J Neurosci Rural Pract. 2013; 4 (3): 250-6.

4. Karibe H, Hayashi $T$, Hirano $T$, Kameyama M, Nakagawa A, Tominaga T. Surgical Management of Traumatic Acute Subdural Hematoma in Adults: A Review. Neurologia medico-chirurgica. 2014; advpub.

5. Rush B, Rousseau J, Sekhon MS, Griesdale DE. Craniotomy versus craniectomy for acute traumatic subdural hematoma in the United States: A national retrospective cohort analysis. World neurosurgery, 2016; 88: 25-31.

6. Kwon YS, Yang KH, Lee YH. Craniotomy or decompressive craniectomy for acute subdural hematomas: surgical selection and clinical outcome. Korean journal of neurotrauma, 2016; 12 (1): 22-7.

7. Bhat AR, Kirmani AR, Wani MA. Decompressive craniectomy with multi-dural stabs-a combined (SKIMS) technique to evacuate acute subdural hematoma with underlying severe traumatic brain edema. Asian journal of neurosurgery, 2013; 8 (1): 15.

8. Khan B, Afridi EAK, Khan B, Khan SA, Aurangzeb A, Khan AA, et al. Decompressive Craniectomy For Acute Subdural Haematoma With Expansile Duraplasty Versus Dural-Slits. Journal of Ayub Medical College Abbottabad, 2016; 28 (2): 285-8.

9. Sakushima K, Hayashino Y, Kawaguchi T, Jackson JL, Fukuhara S. Diagnostic accuracy of cerebrospinal fluid lactate for differentiating bacterial meningitis from aseptic meningitis: a meta-analysis. Journal of Infection, 2011; 62 (4): 255-62.

10. Beck J, Gralla J, Fung C, Ulrich CT, Schucht P, Fichtner J, et al. Spinal cerebrospinal fluid leak as the cause of chronic subdural hematomas in nongeriatric patients. Journal of neurosurgery, 2014; 121 (6): 13807.

11. Bhat AR, Wani MA, Kirmani AR, Raina T, Arif S, Ramzan A. Dural-stabs after wide craniectomy to decompress acute subdural hematoma with severe traumatic brain edema-An alternative technique to open dural flap. Indian Journal of Neurotrauma, 2010; 7 (01): 29-35.

12. Ezri T, Abouleish E, Lee C, Evron S. Intracranial subdural hematoma following dural puncture in a parturient with HELLP syndrome. Canadian Journal of Anesthesia, 2002; 49 (8): 820-3.

13. Barthelemy EJ, Melis M, Gordon E, Ullman JS, Germano IM. Decompressive Craniectomy for Severe Traumatic Brain Injury: A Systematic Review. World Neurosurg. 2016; 88: 411-20.

14. Gelabert-Gonzalez M, Iglesias-Pais M, Fernández-Villa J. Acute subdural haematoma due to ruptured intracranial aneurysms. Neurosurgical review, 2004; 27 (4): 259-62.

15. Koerbel A, Ernemann U, Freudenstein D. Acute subdural haematoma without subarachnoid haemorrhage caused by rupture of an internal carotid artery bifurcation aneurysm: case report and review of literature. The British journal of radiology, 2005; 78 (931): 646-50.

16. Utsunomiya A, Narita N. Spontaneous occipital subdural haematoma. Journal of Neurology, Neurosurgery \& Psychiatry, 2001; 71 (1): 127-. 


\begin{tabular}{|c|c|c|c|}
\hline \multicolumn{4}{|c|}{ AUTHORSHIP AND CONTRIBUTION DECLARATION } \\
\hline Sr.\# & Author's Full Name & Intellectual/Contribution to Paper in Terms of: & \multirow{4}{*}{ 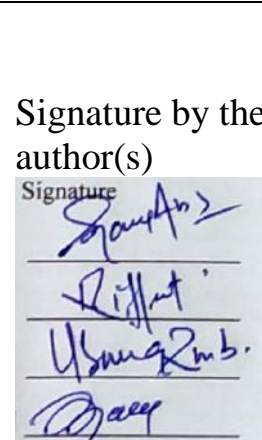 } \\
\hline 1. & $\begin{array}{l}\text { Ghayur Abbas } \\
\text { (Main/Principal Author). }\end{array}$ & $\begin{array}{l}\text { 1. Proposed topics and Basic Study Design, } \\
\text { methodology. }\end{array}$ & \\
\hline 2. & $\begin{array}{l}\text { Riffatullah Khan } \\
\text { (2nd Author) }\end{array}$ & $\begin{array}{l}\text { 2. Data collection and calculations and } \\
\text { methodology }\end{array}$ & \\
\hline 3. & $\begin{array}{l}\text { Usama Bin Zubair } \\
\text { (3rd Author) }\end{array}$ & \multirow{2}{*}{$\begin{array}{l}\text { 3. Analysis of data and interpretation of results, } \\
\text { referencing etc. } \\
\text { 4. Literature review and manuscript writing }\end{array}$} & \\
\hline 4. & $\begin{array}{l}\text { Sajid Nazeer Bhatti } \\
\text { (4th Author) }\end{array}$ & & \\
\hline
\end{tabular}

Date of Submission: 15-07-2019

Date of Revision: 01-08-2019

Date of Online Publishing: 25-09-2019

Date of Print: 30-09-2019 